\title{
Post-operative maternal morbidity and mortality after caesarean delivery and laparotomy for uterine rupture at the gynecology and obstetrics service of the Ignace Deen National Hospital in Guinea
}

\author{
Ibrahima S. Balde ${ }^{1 *}$, Ousmane Balde ${ }^{2}$, Ibrahima Stylla ${ }^{1}$, Alhassane II Sow ${ }^{2}$, Massa Keita ${ }^{1}$, \\ Fatoumata B. Diallo ${ }^{2}$, Ibrahima T. Diallo', Mariame Diallo ${ }^{1}$, Mamadou S. Barry ${ }^{1}$
}

${ }^{1}$ Service Maternite Hospital National Ignace Deen/University, Gamal Abdul Nasser Conakry, Guinea

${ }^{2}$ Service Maternite Hospital National Donka, Conakry, Guinea

Received: 27 August 2020

Accepted: 01 October 2020

*Correspondence:

Dr. Ibrahima Sory Balde,

E-mail: baldeisory@yahoo.fr

Copyright: $@$ the author(s), publisher and licensee Medip Academy. This is an open-access article distributed under the terms of the Creative Commons Attribution Non-Commercial License, which permits unrestricted non-commercial use, distribution, and reproduction in any medium, provided the original work is properly cited.

\begin{abstract}
Background: The aim of the work was to study post-operative maternal morbidity and mortality after caesarean delivery and laparotomy for uterine failure, to describe the main causes and to analyze the risk factors.

Methods: It was a descriptive, comparative and analytical study lasting 2 years with data collection in 2 phases, one of which was a retrospective study lasting one year from July 2018 to June 2019 and the other a prospective study also lasting one year, from July 2019 to June 2020. It concerned all pregnant women who had been caesarized or had had a laparotomy for uterine rupture with complications and those who had not developed any complications. The parameters studied were types of complications, risk factors and maternal mortality. The Chi-square test was used to compare the two populations with a significance level $\mathrm{p}=0.05$.

Results: During the study period, 6141 hospitalizations were recorded among which 5682 surgical procedures were performed, i.e. $92.52 \%$ of hospitalizations. Caesarean delivery accounted for $90.55 \%$ of surgical procedures and laparotomy for uterine rupture for $1.10 \%$. The overall maternal post-operative morbidity rate was $7.60 \%$. Post-operative anemia was by far the most common complication $(75.76 \%)$ followed by infection $(23.46 \%)$. The maternal death rate was $0.92 \%$ with a ratio of 409.97 maternal deaths per 100,000 live births and more than $2 / 3$ of these deaths were due to caesarean delivery. Anemia and septic shock were the main causes of death. Factors related to this post-operative maternal morbidity were: age greater than or equal to 40 years, multi-parity, illiteracy, emergency obstetric evacuation, low socio-economic level, poor quality of prenatal follow-up and rupture of membranes before admission.

Conclusions: In the emergency context concerning majority of our cesarean deliveries and the totality of uterine ruptures predispose the mother to high significant morbidity and mortality.
\end{abstract}

Keywords: Morbidity, Maternal mortality, Post-operative, Caesarean delivery, Uterine rupture, Ignace Deen

\section{INTRODUCTION}

Perfect mastery of surgical techniques and the use of antibiotics make any surgical acts simple and harmless. However, this is not the case in Black Africa. Morbidity and mortality per and post-surgery remain high. The main causes are haemorrhage and infection. Maternal morbidity and mortality is a major public health problem in developing countries, where $99 \%$ of maternal deaths worldwide. ${ }^{1}$ The rate of maternal mortality in the African region remains low (1.7\%) and corresponds to a mortality rate of 620 of 100,000 births livings in $2008 .^{2}$ Despite technical, organizational and financial efforts made, maternal mortality is still very high in Guinea, 576 of 100,000 births livings. ${ }^{3}$ However, surgical interventions are unavoidable in certain situations that require the 
removal of the pregnant woman from the complications of obstructed labor.

Lack of knowledge of the field in which the surgeon works (absence of pre-operative check-up due to the emergency) multiplies the surgical risks. In addition, the frequency of surgical interventions tends to increase due to the creation of more and more SONUC (obstetric and neo-natal emergency care services) in other districts of the city of Conakry, structures serving as a relay between the basic health structures (health centre) and the referral service (CHU). It therefore seemed necessary to us to assess the risks associated with this practice in order to improve the management of pregnant and parturient who have been operated and to remove as possible from any eventual dangers.

The aim of the work was to study the post-operative maternal morbidity and mortality after caesarean delivery and laparotomy for uterine rupture, to describe the main causes and analyze the risk factors.

\section{METHODS}

\section{Case study}

The study took place in the gynecology and obstetrics department of the Ignace Deen National Hospital, currently the only referral maternity hospital in the city of Conakry.

\section{Type and duration of study}

It is about descriptive, comparative and analytical study for the duration of 2 years of data collection in 2 phases, one is for one year, retrospective study from July, 2018 to June, 2019 and the other is for one year prospective study from July, 2019 to June, 2020.

\section{Characteristics of the population}

Target population:It consisted of all pregnant women benefiting from the services at the study site.

Study population: It concerned all pregnant women who were cesarized or who had a laparotomy for uterine rupture with complications and those who did not develop any complications.

\section{Inclusion criteria}

The study included all pregnant women and parturient who had undergone caesarean delivery or laparotomy for uterine rupture with or without post-operative pathology.

\section{Exclusion criteria}

The exclusion criteria were not included in the study, all women who had received another intervention.

\section{Data collection}

For the retrospective part, data were collected from management tools (medical records, childbirth or delivery register, surgical report register, medical agent report register, hospitalization register and the register of maternal deaths).

For the prospective part, the data was collected using the management tools mentioned above and the patients selected for the study were interviewed and examined daily from admission to discharge of pathologies that had occurred in the post-operative period.

Complementary tests have been requested to confirm certain diagnoses. Was considered maternal morbidity post-operative, any pathology occurring in the postoperative.

\section{Data analysis}

The data collected was typed and analyzed using a software (Epi info) version 7. The statistical test used is the Pearson chi square. The Chi-square test was used to compare the two populations with a significance level of $5 \%(\mathrm{p}=0.05)$.

\section{RESULTS}

\section{Frequency}

During the study period, 6141 hospitalizations were recorded among which 5682 surgical procedures were performed, i.e. $92.52 \%$ hospitalizations.

Caesarean delivery represented $90.55 \%$ surgical procedures $(n=5145)$ and $83.78 \%$ hospitalizations. Laparotomy for uterine rupture represented $1.10 \%$ surgical procedures $(n=63)$ and $1.02 \%$ of hospitalizations.

\section{Maternal post-operative morbidity}

\section{Frequency of post-operative maternal complications}

Post-operative outcomes were complicated in $7.60 \%$ of surgical procedures for caesarean delivery and laparotomy for uterine rupture compared to $92.40 \%$ of simple postoperative outcomes.

\section{Risk factors of post-operative maternal morbidity}

\section{Socio-demographic characteristics}

\section{Maternal age}

Study revealed that the age group more than or equal to 40 years was the high-risk factor of post-operative maternal complications with significant difference $(\mathrm{p}=0,000)$. 
Mode of admission

Analysis of this parameter reveals that the risk of postoperative maternal complications after caesarean delivery and laparotomy for uterine rupture was 2 times higher to the parturient evacuated to that of non-evacuated parturient, i.e. $12.56 \%$ versus $5.40 \%$ with a significant difference $(\mathrm{p}=0.000)$.

\section{Socio-professional category}

Analysis of this parameter reveals that the risk of postoperative maternal complications was higher among housewives, with $9.18 \%$ compared to $4.16 \%$ among salaried employees, with a significant difference $(\mathrm{p}=0.000)$.

\section{Educational level}

The risk of occurrence of a post-operative complication was higher among women with no schooling and those with primary education respectively $10.72 \%$ and $10.59 \%$ with statistically significant difference $(\mathrm{p}=0.000)$.

\section{Surgical intervention context}

The risk of post-operative complications was higher if the intervention was performed in an emergency context, i.e. $8.52 \%$ versus $4.44 \%$ if the intervention was scheduled (caesarean delivery); the differences observed were statistically significant.

Table 1: Frequency of caesarean delivery and laparotomy for uterine rupture in relation to all surgical procedures.

\begin{tabular}{|lll|}
\hline Interventions & Number & $\%$ \\
\hline Cesarean & 5145 & 90.55 \\
\hline Laparotomy for rupture uterine & 63 & 1.10 \\
\hline Laparotomy for GEU & 131 & 2.31 \\
\hline Myomectomy & 194 & 3.41 \\
\hline Hysterectomy & 113 & 2 \\
\hline Bistournage & 8 & 0.14 \\
\hline Operation musset & 5 & 0.09 \\
\hline Salpingoplasty & 2 & 0.04 \\
\hline Tumerectomy & 2 & 0.04 \\
\hline Prolapse cure without hysterectomy & 3 & 0.05 \\
\hline Pelviperitonitis & 5 & 0.09 \\
\hline Annexectomy & 4 & 0.07 \\
\hline Others & 7 & 0.12 \\
\hline Total & 5682 & 100 \\
\hline
\end{tabular}

Table 2: Frequency types of maternal complications.

\begin{tabular}{|lllllll|}
\hline \multirow{2}{*}{ Types of complications } & \multicolumn{2}{l}{ Caesarean } & \multicolumn{2}{l}{ Laparotomy for } \\
rupture uterine & \multicolumn{2}{c|}{ Total } \\
& $\mathbf{N}$ & $\mathbf{\%}$ & $\mathbf{N}$ & $\mathbf{\%}$ & $\mathbf{N}$ & \% \\
\hline Anemia & 264 & 75.86 & 36 & 75 & 300 & 75.76 \\
\hline $\begin{array}{l}\text { Partietal suppuration with or } \\
\text { without release of thread }\end{array}$ & 61 & 17.52 & 08 & 16.66 & 69 & 17.42 \\
\hline Hemorrhage & 41 & 11.78 & 02 & 4.16 & 43 & 10.85 \\
\hline Endometritis & 08 & 2.29 & 02 & 4.16 & 10 & 2.52 \\
\hline Sepsis & 05 & 1.43 & 02 & 4.16 & 07 & 1.76 \\
\hline Eclampsia & 09 & 2.58 & 00 & 00 & 09 & 2.27 \\
\hline Urinary tract infections & 04 & 1.14 & 03 & 6.25 & 07 & 1.76 \\
\hline Acute urine retention & 02 & 0.57 & 00 & 00 & 02 & 0.50 \\
\hline Stroke & 01 & 0.28 & 00 & 00 & 01 & 0.25 \\
\hline Bowel obstruction & 01 & 0.28 & 01 & 2.08 & 02 & 0.50 \\
\hline Acute renal failure & 01 & 0.28 & 00 & 00 & 01 & 0.25 \\
\hline PAO & 01 & 0.28 & 00 & 00 & 01 & 0.25 \\
\hline Thrombophlebitis & 01 & 0.28 & 00 & 00 & 01 & 0.25 \\
\hline
\end{tabular}


Table 3: Surgical outcome according to parity.

\begin{tabular}{|llllll|}
\hline Surgery outcome & Primipare & Paucipare & Multipare & Large multipare & Total \\
\hline With complications & $94(5.71 \%)$ & $156(7.29 \%)$ & $86(8.6 \%)$ & $60(14.18 \%)$ & $396(7.60 \%)$ \\
\hline Without complications & $1552(94.29 \%)$ & $1983(92.71 \%)$ & $914(91.4 \%)$ & $363(85.82 \%)$ & $4812(92.40 \%)$ \\
\hline Total & 1646 & 2139 & 1000 & 423 & $5208(100 \%)$ \\
\hline
\end{tabular}

$\mathrm{P}=0.0000$.

Table 4: Surgical outcome according to NPC.

\begin{tabular}{|c|c|c|c|c|c|c|}
\hline Surgery outcomes & $\mathbf{0}$ & 1 & 2 & 3 & $\geq 4$ & Total \\
\hline With complications & $37(25.51 \%)$ & $45(13.63 \%)$ & $97(9.88 \%)$ & $\begin{array}{l}121 \\
(5.44 \%)\end{array}$ & $96(6.28 \%)$ & $396(7.60 \%)$ \\
\hline $\begin{array}{l}\text { Without } \\
\text { complications }\end{array}$ & $\begin{array}{l}108 \\
(74.49 \%)\end{array}$ & $\begin{array}{l}285 \\
(86.37 \%)\end{array}$ & $\begin{array}{l}884 \\
(90.12 \%)\end{array}$ & $\begin{array}{l}2102 \\
(94.56 \%)\end{array}$ & $1433(93.72 \%)$ & $4812(92.40 \%)$ \\
\hline Total & 145 & 330 & 981 & 2223 & 1529 & $5208(100 \%)$ \\
\hline
\end{tabular}

Table 5: Surgical outcome according to NPC.

\begin{tabular}{|lllllll|}
\hline $\begin{array}{l}\text { Surgery outcomes } \\
\text { With }\end{array}$ & CS & CMC & CHU & No NPC & Private & Total \\
complications & $192(8.16 \%)$ & $63(7.88 \%)$ & $26(4.30 \%)$ & $36(25 \%)$ & $79(6.04 \%)$ & $396(7.60 \%)$ \\
\hline $\begin{array}{l}\text { Without } \\
\text { complications }\end{array}$ & $\begin{array}{l}2160 \\
(91.84 \%)\end{array}$ & $\begin{array}{l}736 \\
(92.12 \%)\end{array}$ & $579(95.70 \%)$ & $\begin{array}{l}108 \\
(75 \%)\end{array}$ & $\begin{array}{l}1229 \\
(93.96 \%)\end{array}$ & $4812(92.40 \%)$ \\
\hline Total & 2352 & 799 & 605 & 144 & 1308 & $5208(100 \%)$ \\
\hline
\end{tabular}

Table 6: Surgery sequences in function of membrane rupture deadline.

\begin{tabular}{|c|c|c|c|c|}
\hline $\begin{array}{l}\text { Surgery } \\
\text { outcome }\end{array}$ & $\begin{array}{l}\text { Less than } 24 \\
\text { hours }\end{array}$ & $\begin{array}{l}\text { Greater than } 24 \\
\text { hours }\end{array}$ & Intact & Total \\
\hline With complications & $92(4.74 \%)$ & $39(4.28 \%)$ & $265(13.50 \%)$ & $396(7.60 \%)$ \\
\hline Without complications & $1939(95.26 \%)$ & $910(95.18 \%)$ & $1963(86.50 \%)$ & $4812(92.40 \%)$ \\
\hline Total & 2031 & 949 & 2228 & $5208(100 \%)$ \\
\hline
\end{tabular}

\section{Factors related to pregnancy}

Number of pre-natal consultations (NPC)

Places for pre-natal consultations

State of egg membranes

After analysis of this parameter we obtained, 3718 patients were admitted with intact membranes, including 271 cases of complications, i.e. $7.29 \%$ incidence;

1490 patients admitted with ruptured membranes, including 125 cases of post-operative complications, i.e. $8.39 \%$ without significant difference

\section{Deadline of ruptures membranes}

\section{Maternal mortality}

Of 5208 cases of caesarean deliveries and laparotomies for uterine rupture, we recorded 48 maternal deaths, i.e. globally $0.92 \%$ with a ratio of 409.97 maternal deaths of 100,000 birth livings.

Of 2159 pregnant women and parturients evacuated, we recorded 40 maternal deaths, i.e. a lethality of $1.85 \%$ versus $0.26 \%(8 / 3049)$ in patients coming directly from their home (not evacuated).

\section{DISCUSSION}

\section{Limits and bias}

The Gynecology-Obstetrics Department of the Ignace Deen National Hospital is currently the only functional referral center receiving all complicated pregnancy and childbirth cases from the city of Conakry and the interior of the country. This proved high maternal morbidity and mortality.

Some women discharged from hospital never appeared back for follow-up. Their re-examination may have changed the rate of maternal morbidity and mortality. Again, maternal mortality is therefore underestimated 
because patients who died at home before day 42nd day were not counted.

\section{Post-operative maternal morbidity}

Post-operative complications were complicated to $7.60 \%$ of the patients in our sampling. This 1 post-operative maternal morbidity rate is significantly lower than that reported by Akotionga et al, i.e. 50.1\%, and that of the African average, which was 30 to $40 \% 30$ years ago. ${ }^{4,5}$ This could be explained by various reasons: the progress made in terms of asepsis in the operating room on the one hand and due to the introduction of free caesarean deliveries, albeit temporarily partial, on the other hand, thus improving per- and post-operative care and the increase in the number of qualified personnel in the service on one hand, and on the other hand the improvement of the aptitude of the personnel of peripheral maternity hospitals to diagnose and take care of or evacuate obstetric emergencies to the referral service in a timely manner through various training workshops in SONUC (emergency obstetric and neo-natal care) organized throughout the territory; we can say that the figure could be lower if it were shared between the two services.

Overall, this operative morbidity was variable depending on the operative indication.

\section{Caesarean delivery}

Caesarean deliveries represented $90.55 \%$ of surgical procedures in the department during the study period. Among these women, $6.68 \%$ had at least one postoperative complication, a lower rate than that reported 12 years ago by Baldé in the same service $(9.90 \%){ }^{6}$ The reasons are the same as those previously advanced in relation to the overall rate of post-operative morbidity.

Anemia occupied the first place with $75.86 \%$, followed by infection (parietal suppuration, endometritis, septicemia, urinary tract infection) with $22.38 \%$. Our result is contrary to that reported by Akotionga in Fasso reporting a predominance of infection $(80.6 \%)$ and that of Baldé et al in the same service in 2008 reporting infection as a major cause of morbidity in caesarean patients (76.2\%).,6 This rate of post-operative infection, although not higher, is not negligible and could be explained by the lack of hygiene, growing poverty and also the terrain in which surgery is performed (water pouch broken for more than 24 hours with often a beginning infection) which would favor it: majority of patients who are not or poorly followed up often arrive in emergency room; also not to forget about the septic working conditions (lack of operating linen).

The high rate of post-operative anemia in our series is thought to be related to malnutrition, multi parity with close pregnancies, chronic anemia caused by parasitosis, and intraoperative hemorrhage during caesarean delivery.
In Côte d'Ivoire, according to the work of Touré et al postcaesarean delivery anemia was the most frequent complication. ${ }^{7}$ In Mali, Diawara et al reported infection as the most frequent post caesarean delivery complication. ${ }^{8}$

\section{Uterine rupture}

We have performed 63 laparotomies for uterine rupture, i.e. one uterine rupture for 81 caesarean deliveries.

Post-operative morbidity in uterine rupture was $76.19 \%$. This high morbidity could be explained in the same way as encountered in caesarean delivery.

Anemia again took place here with a rate of $75 \%$, followed by infection with $31.23 \%$. Our findings are similar to those of Diallo et al at Donka's sister hospital in Conakry, who reported anemia and infection as the most frequent complications after laparotomy for uterine rupture ( $19.38 \%$ and $20.08 \%$ respectively) ${ }^{9}$

\section{Risk factors of post-operative maternal morbidity}

The increased risk of post-operative complications in women aged 40 years or older could be explained by the fact that advanced age is often associated with medical pathologies during pregnancy (hypertension, diabetes). Compared to parity, it appears that the risk of postoperative maternal complications was greater in large multiparous and multiparous women with an incidence of $14.18 \%$ and $8.6 \%$ respectively.

The uterus of large multiparous women is often flaccid, which favors fetopelvic accommodation disorders during labor with its corollary of evacuation from peripheral maternity wards over long distances. Our conclusions are similar to those of Talle in Côte d'Ivoire and Akotionga in Fasso, who reported a risk of $79.5 \%$ and $77.77 \%$ respectively in large multiparous women. ${ }^{4,10}$ In reality, parity alone cannot be considered as a risk factor; it is most often the interplay of several factors, notably: age, of admission mode (emergency obstetric evacuation) and socio-economic level.

The increased risk of post-operative complications among evacuees could be explained by the fact that most often they are parturient, mostly from peripheral maternity hospitals or delivery homes (illegal health facilities run by retired health workers or matrons) where there have been several hours or even days of unsuccessful attempts to deliver vaginal deliveries during which a problem has arisen. The increased risk among housewives could be explained by the fact that they are generally illiterate women with no source of income, who are mostly involved in the follow-up activities of the family, on which they depend heavily. These women have to wait for their husbands or other family members to meet the expenses inherent to their health status, resulting in delays in seeking emergency obstetric and neo-natal care services. 
With regard to the context of the surgical procedure, the risk of a post-operative complication is higher when the procedure was performed in an emergency context than if the procedure was scheduled (caesarean delivery). For Van, serious complications (delivery bleeding, pelvic infection, bleeding disorder, operative wounds) are significantly less frequent when caesarean delivery is performed before labor $(2.6 \%)$ than when it is performed during labor $(5.2 \%) .{ }^{11}$

The importance of infection in the emergency room often reveals late obstetric evacuation, evacuation conditions, and difficulties in management. It should also be noted that the intervention is carried out in a field that is conducive to infection (premature rupture of membranes, genitourinary infection, and anemia) without forgetting the septic conditions of labor, pregnant women undergoing numerous vaginal touches in a context of dubious asepsis, the water sac having been ruptured for several hours. We thus join Boulanger. ${ }^{12}$ These different observations are explained by the fact that: emergency caesarean deliveries and laparotomies for uterine rupture are decided in pregnant women in labor, most of whom are evacuated urgently from peripheral maternity hospitals or delivery centres after several hours of unsuccessful attempts to deliver by the vaginal route, with a water sac that has been ruptured for several hours. They often arrive by nonmedical means of transport (taxi, private car), sometimes in a state of septic shock, or hypovolemic, malnourished and exhausted. Caesarean deliveries performed in these conditions with excessively high infectious risk factors affecting the maternal-fetal prognosis, and lengthen the duration of maternal hospitalization; prophylactic caesarean deliveries are by definition scheduled, the patient is known, a preoperative check-up is performed, abnormalities such as anemia are ruled out or corrected, and the ovarian membranes are intact, thus reducing the risk of infection.

The condition of the membranes on admission is decisive in the postpartum series. When the membranes are ruptured, the egg is opened, exposing both mother and child to infection. Our results are similar to those of Talle who concluded that there are $57.8 \%$ of post-caesarean delivery maternal complications when the membranes have been ruptured for less than 12 hours, a figure that rises to $81.1 \%$ for more than 12 hours. ${ }^{10}$

Concerning the time to rupture the membranes (time between the moment of rupture and the intervention), there is an incidence of $4.5 \%$ for the time less than 24 hours versus $4.13 \%$ for the time more than 24 hours with no significant difference. Our results are different from those reported by Akotionga et al who concluded that for a time between 0 and 24 hours, there were $44.9 \%$ complications, and for a time longer than 24 hours, there were $69 \%$ complications. ${ }^{4}$

This difference could be explained by the fact that in our series, the most frequent post-operative complication was anemia, unlike the Akotionga series where infection was the most frequent complication $(90.4 \%)$ compared to $22.98 \%$ of infectious morbidity in our series. ${ }^{4}$

\section{Maternal mortality}

More than $2 / 3$ of maternal deaths $(85.41 \%)$ were the result of a caesarean delivery.

The mortality rate for caesareans was $0.79 \%$, lower than that of Diawara et al in Mali. ${ }^{8}$ Our non-negligible maternal death rate could be explained by late obstetric evacuations. For Touré et al in Abidjan, it is the operative indication that is the predominant factor, as only $10 \%$ of the causes of maternal death are attributed to caesarean delivery. ${ }^{7}$

Among the uterine ruptures, the deaths recorded after their surgical treatment are seven or $11.11 \%$. Of the seven patients who died, six were evacuated, i.e. $85.71 \%$. Five deaths had occurred as a result of acute anemia and the others in a septic shock table.

Age, illiteracy and poor prenatal monitoring are all factors that make the condition of our patients in the postoperative period precarious.

\section{CONCLUSION}

This work shows that post-operative morbidity after caesarean delivery and laparotomy for uterine rupture remains high at $7.60 \%$. Anemia was the most common post-operative condition. The main causes of postoperative maternal death were anemia and septic shock.

Funding: No funding sources Conflict of interest: None declared

Ethical approval: The study was approved by the Institutional Ethics Committee

\section{REFERENCES}

1. Robitol S, Gode S, Barran K, Tremouille S, Belec M. What is the cost of a Caesarean delivery in Madagascar? Socio-demographic aspects and Caesarean delivery coverage rate in Toamacina 19992007. Pub Health. 2003;274-9.

2. WHO: World Health Statistics. 2011;170:15. Accessed on 20 July, 2020.

3. Demographic and Health Survey (EDS V) Guinea 2018. National Institute of Statistics. The DHS program, ICF. Rockville, Maryland, USA. 2019:15178. Accessed on 20 July, 2020.

4. Akotionga M, Sawadogo Y, Lankoandé J, Koné B. Postoperative maternal morbidity and mortality in an African environment. About 583 cases of EP, Caesarean deliveries and uterine ruptures at the National Hospital Center of Ouagadougou. Rev Fr Gynaecol Obstetrics. 1999;94(6):460-6. 
5. Pambou O, Guyot B, Antoine JM, Salat Baroun. Gynecological endoscopic surgery in Africa: luxury or necessity? Rev Fr Gynecol Obstet. 1990;90:174-7.

6. Baldé IS, Sy T, Diallo MC, Diallo Y, Soumah FM, Diallo A, et al. Maternal complications after Caesarean delivery at the Gynecology-Obstetrics Department.Anales de la SOGGO. 2008;11(3):170-5.

7. Touré, Coulibaly K Anongba S, Aissi GA. Indications for Caesarean delivery. About 754 cases collected at the maternity hospital of Treichville. Communication of the 3rd congress of the SAGO, Abidjan 1996.

8. Diawara A, Sangho H, Tangara I, Cissé MO, Traoré MN, Konaté S. Post-caesarean delivery complications and free caesarean delivery in Mali: the case of a district health centre. Mali médical. 2014;(1)45-9.

9. Diallo MH, Baldé IS, Mamy MN, Diallo BS, Baldé O, Barry $\mathrm{AB}$, Keita $\mathrm{N}$. Uterine rupture: sociodemographic aspect, etiology and management. Med Santé Trop. 2017;27:305-9.

10. Talle B. Maternal post-caesarean delivery complications (about 828 caesarean deliverys performed in 1999 in the maternity ward of the
Treicheville University Hospital. CES dissertation. Gynecol Obstét. 2000;596.

11. Ham VM, Van Dogen PW, Mulder J. Matrenal consequences of caesarean delivery. A retrospective study of intra operative and prospective maternal complications of ceasarean delivery during a 10 years period. Eur J Obstet Gynecol Biol. 1997;74:1-6.

12. Boulanger JC, Vist M, Berh VB, Cauner B, Caron C, Firmin JM. Maternal complications of caesarean deliveries. J Gynécol Obstét Biol Repro. 1986;15:327.

Cite this article as: Balde IS, Balde O, Stylla I, Sow AII, Keita M, Diallo FB et al. Post-operative maternal morbidity and mortality after caesarean delivery and laparotomy for uterine rupture at the gynecology and obstetrics service of the Ignace Deen National Hospital in Guinea. Int J Reprod Contracept Obstet Gynecol 2020;9:4367-73. 